\title{
A Web Application for Self-Monitoring Improves Symptoms in Chronic Systolic Heart Failure
}

\author{
Michael P. Dorsch, PharmD, MS, ${ }^{1}$ Karen B. Farris, $P h D_{1}{ }^{2}$ \\ Barry E. Bleske, PharmD, ${ }^{2}$ and Todd M. Koelling, $M D^{3}$

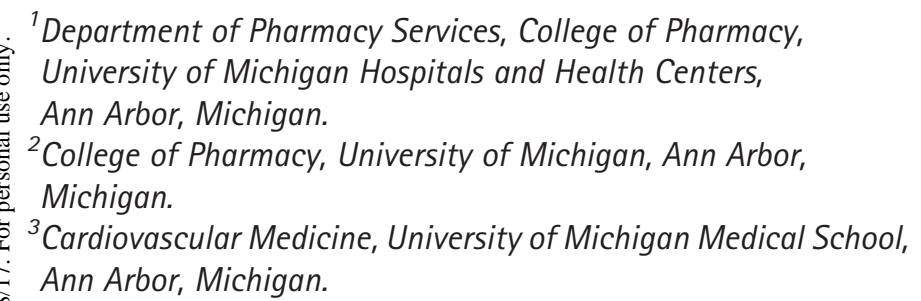

\section{Abstract}

Objective: The objective of this study was to determine if a Web application that promoted mindfulness of the progress of the chronic disease through self-monitoring improved quality of life in heart failure. Materials and Methods: This was a prospective singlecenter single-group study. Participants were instructed how to use the Web application and to perform self-monitoring daily for 12 weeks. A comprehensive physical exam, assessment of New York Heart Association (NYHA) class, the Minnesota Living with Heart Failure Questionnaire (MLHFQ), and an evaluation of selfmanagement were performed in person at baseline and at 12 weeks. . Results: Participants consisted of older (mean, 59 years), predominantly female (63\%) adults with NYHA class II or III symptoms. NYHA classification (preintervention versus postintervention, $2.5 \pm 0.13$ versus $2.0 \pm 0.13 ; \mathrm{p}=0.0032)$ and $M L H F Q$ score (55.7 \pm 4.6 versus $42.6 \pm 5.1$, respectively; $\mathrm{p}=0.0078)$ improved over 12 weeks of self-monitoring. A trend toward improvement was also demonstrated in weight (preintervention versus postinterven-

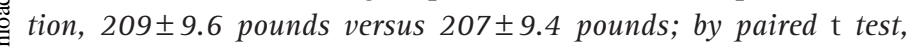
$\mathrm{p}=0.389)$, number of times exercised per week (1.29 \pm 0.5 versus $2.5 \pm 0.6$, respectively; $\mathrm{p}=0.3$ ), and walk distance (572 \pm 147 yards versus $845 \pm 187$ yards, respectively; $\mathrm{p}=0.119$ ). Jugular venous distention (preintervention versus postintervention, $8.1 \pm 0.6 \mathrm{~cm}$ versus $6.7 \pm 0.3 \mathrm{~cm} ; \mathrm{p}=0.083)$ and peripheral edema $(29.2 \%$ versus $16.7 \%$, respectively; $\mathrm{p}=0.375)$ decreased after 12 weeks of selfmonitoring via the Web application. Conclusions: A Web application for self-monitoring heart failure over 12 weeks improved both NYHA classification and MLHFQ score. The trend in improved physical activity and physical exam support these outcomes. The number of patients reporting a sodium-restricted diet increased over the 12 weeks, which may have led to the positive findings.

Key words: congestive heart failure, health informatics, self-monitoring

\section{Introduction}

I

$\mathrm{n}$ the United States, heart failure (HF) is the most common hospital discharge diagnosis among the elderly. Eighty-three percent are hospitalized at least once, and 43\% are hospitalized at least four times from the initial diagosis. ${ }^{1}$ Previous research shows that case management and telephonic support may be effective in reducing HF hospitalizations, but these strategies are costly. Although studies have implemented technologically driven disease management programs, results have been mixed. The important gap in these systems is that they focus on delivering the monitoring data to the healthcare provider, not the patient. Several recent studies along with a systematic review have demonstrated that self-management is a key component of an HF care program. ${ }^{2-5}$ Such programs emphasize self-management strategies, including daily recording of body weight, maintaining an HF diary to monitor weight and to detect early symptoms, ensuring adherence to pharmacological and nonpharmacological treatment, and self-adjustment of diuretics.

Self-management is defined as an active cognitive process undertaken by the patient to manage his or her HF, typically the adoption of self-monitoring such as self-weighing, sodium restriction, fluid restriction, and monitoring of symptoms. ${ }^{6}$ This results in the patient interpreting the changes in his or her self-monitoring and performing self-management. The purpose of this study was to determine if a Web application that promoted mindfulness of the progress of the chronic disease through self-monitoring improved quality of life in HF.

\section{Materials and Methods STUDY DESIGN}

This was a prospective single-center single-group pre- and postintervention study design. Patients were enrolled from the University of Michigan Frankel Cardiovascular Center Advanced Heart Failure Clinic (Ann Arbor, MI). Patients were included with systolic HF and an ejection fraction of less than 40\%. Patients were excluded if they did not have a home computer with Internet access and could not use the Internet. Participants were given instructions about how to use the Web site application and to perform self-monitoring daily for 12 weeks. Daily self-monitoring included blood pressure, heart rate, weight, and four questions about their HF symptoms (Fig. 1). If the answer to Question 4 was "worsened," then the patient was prompted to answer more questions to elucidate what specifically changed since the previous day (see Supplementary Table S1; Supplementary Data are available online at www.liebertpub.com/tmj). Regardless of symptoms, the Web site provided a link to a standardized list of HF self-care goals along with links to the University of Michigan Health 


\section{DORSCH ET AL.}

\begin{tabular}{|l|}
\hline $\begin{array}{l}\text {-Did you take all of your } \\
\text { prescribed medications in the }\end{array}$ \\
last 24 hours? \\
$\begin{array}{l}\text {-Did you follow your fluid } \\
\text { restrictions in the last } 24 \\
\text { hours? }\end{array}$ \\
$\begin{array}{l}\text {-Did you follow your sodium } \\
\text { restrictions in the last } 24 \\
\text { hours? }\end{array}$ \\
$\begin{array}{l}\text { - Compared with yesterday, } \\
\text { how have your symptoms of } \\
\text { heart failure (shortness of } \\
\text { breath, fatigue or ankle } \\
\text { swelling) changed? }\end{array}$ \\
\hline
\end{tabular}

Fig. 1. Screen shot of daily self-monitoring questions about heart failure symptoms.

System HF educational documents and the Heart Failure Society of America's $11 \mathrm{HF}$ education modules (see Supplementary Table S2). Optional monitoring of exercise and nutrition within the Web application was available at the patient's choosing. All monitoring was aggregated in the "My Progress" section of the Web application for the patient to view his or her progress.

\section{OUTCOME MEASURES}

A comprehensive physical exam and assessment of New York Heart Association (NYHA) class was performed by an HF cardiologist; a Minnesota Living with Heart Failure Questionnaire (MLHFQ) and an evaluation of self-management tasks were measured in person at baseline and at 12 weeks. NYHA class is an objective measurement of functional status and was assessed by an HF cardiologist based on the symptoms of the patient. MLHFQ is a quality of life assessment that takes into account 21 facets of living with HF and uses a 5-point Likert scale.

\section{STATISTICAL ANALYSIS}

The main outcomes were the change in NYHA classification and MLHFQ from baseline to follow-up. Paired $t$ test, the Wilcoxon rank sum test, and McNemar's test were performed where appropriate. Continuous data are represented as mean \pm standard error values. All statistical analyses were performed using SAS software version 9.3 (SAS Institute Inc., Cary, NC).

\section{Results}

In total, 43 patients were enrolled in the study, but only 24 used the Web application for self-monitoring and completed the baseline and 12 -week assessments. Of the 24 patients, the median duration using the Web application was 67 days. In general, the participants consisted of older (mean, 59 years), predominantly female (63\%) adults with NYHA class II or III symptoms. Baseline characteristics are given in Table 1.

Both NYHA classification (preintervention versus postintervention, $2.5 \pm 0.13$ versus $2.0 \pm 0.13$; by Wilcoxon rank sum test, $p=0.0032)$ and MLHFQ score (55.7 \pm 4.6 versus $42.6 \pm 5.1$, respec-

\begin{tabular}{l|c} 
Table 1. Baseline Characteristics & \multicolumn{1}{c}{ VARIABLE } \\
Age (years) & $59 \pm 9$ \\
\hline Female gender (\%) & $63(15)$ \\
\hline Ejection fraction (\%) & $28 \pm 10$ \\
\hline Hospitalizations in the last year (\%) & $54(13)$ \\
\hline 0 & $46(11)$ \\
\hline 1 or more & $83(20)$ \\
\hline ICD (\%) & $58(14)$ \\
\hline Coronary artery disease (\%) & $54(13)$ \\
\hline HTN (\%) & $38(9)$ \\
\hline Atrial fibrillation (\%) & $33(8)$ \\
\hline Diabetes (\%) & \\
\hline $\begin{array}{l}\text { Data are mean } \pm \text { standard error or percentage }(n) \text { as indicated. } \\
\text { HTN, hypertension; ICD, implantable cardioverter-defibrillator. }\end{array}$ \\
\hline
\end{tabular}

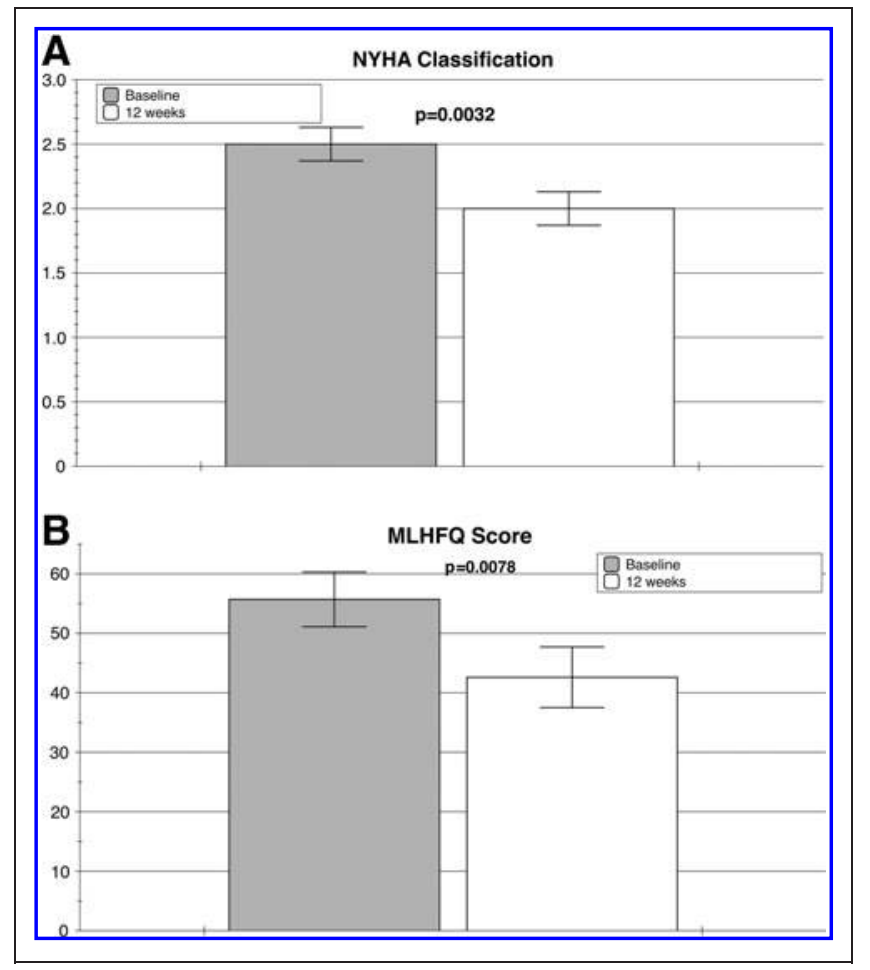

Fig. 2. Baseline and 12 weeks after a Web application self-monitoring intervention: (A) change in New York Heart Association (NYHA) classification and (B) change in Minnesota Living with Heart Failure Questionnaire (MLHFQ) score. 
tively; by paired $t$ test, $p=0.0078$ ) improved significantly after 12 weeks of self-monitoring via the Web application (Fig. 2). A trend toward improvement was also demonstrated in weight (preintervention versus postintervention, $209 \pm 9.6$ pounds versus $207 \pm 9.4$ pounds; by paired $t$ test, $p=0.389$ ), number of times exercised per week $(1.29 \pm 0.5$ versus $2.5 \pm 0.6$, respectively; by Wilcoxon rank sum test, $p=0.3$ ), and walk distance ( $572 \pm 147$ yards versus $845 \pm 187$ yards, respectively; by Wilcoxon rank sum test, $p=0.119$ ).

Trends in a positive direction were also demonstrated in the HF physical exam. Jugular venous distention (preintervention versus postintervention, $8.1 \pm 0.6 \mathrm{~cm}$ versus $6.7 \pm 0.3 \mathrm{~cm}$; by Wilcoxon rank $\therefore$ sum test, $p=0.083)$ and peripheral edema (29.2\% versus $16.7 \%$, respectively; by McNemar's test, $p=0.375$ ) decreased after 12 weeks of self-monitoring via the Web application.

To further delineate the potential modifiers of these effects, paڤ. tients were questioned about self-management strategies. There was no difference in patient report of following a fluid restriction (preintervention versus postintervention, $95.8 \%$ versus $95.8 \%$; by IcNemar's test, $p=1.0$ ) or the number of times weight was moniज tored per week $(6.2 \pm 0.4$ versus $5.9 \pm 0.5$, respectively; by Wilcoxon rank sum test, $p=1.0$ ). There was, however, a trend toward an increase in the number of patients who reported following a sodiumrestricted diet (preintervention versus postintervention, 62.5\% versus $79.2 \%$, respectively; by McNemar's test, $p=0.29$ ) at 12 weeks comzared with baseline.

\section{Discussion}

In this small pilot study, a Web application that promoted mindfulness of chronic disease progress through self-monitoring showed statistically and clinically meaningful changes in both NYHA clasi sification and MLHFQ score. In fact, although these two measurements . studies. Validation of the MLHFQ has shown that scores of 21, 37, 53, and 69 approximately correspond to NYHA class I, II, III, and IV, re嘀 spectively. ${ }^{7}$ Although not statistically significant, it is also supportive that we demonstrate an improvement in physical exam, presence of a peripheral edema, and the extent of jugular venous distention, as well as markers of activity, number of times walked per week, and walk distance. These corroborate the main outcomes of this pilot study.

Q Recently, a similar study was performed to demonstrate the effect of symptom diary with education and counseling sessions compared with usual care in $44 \mathrm{HF}$ patients. ${ }^{8}$ Although this randomized controlled trial study did not show an improvement in health-related quality of life, it did reveal that patients keeping a symptom diary with education and five counseling sessions reduced event-free survival compared with usual care (78.3\% active group versus 47.6\% usual care; $p=0.03) .{ }^{8}$ Encouraging results have also been found in earlier studies. Caldwell et al. ${ }^{9}$ showed that daily weight monitoring along with education improved knowledge and self-care related to weight monitoring. Doughty et al. ${ }^{10}$ performed a randomized clinical trial enrolling 197 patients of an intervention group, which consisted of an HF diary and education about HF self-management, compared with usual care over a 12-month period. At 12 months, im- plementation of daily weight monitoring and level of education on self-management were significantly higher in the intervention group compared with usual care. ${ }^{11}$ The intervention had no effect on time to death or hospital re-admission but decreased total bed-days and multiple re-admissions and improved patient quality of life. Results of these studies support our findings that promotion of selfmonitoring including through a Web-based application can improve the management of a patient's HF.

When determining which self-management tasks may have contributed to our positive finding, the number of patients reporting a sodium-restricted diet was higher on follow-up. Self-monitoring helps the patient focus his or her attention on symptom and weight changes. We believe that the mindfulness of self-monitoring provided feedback to the participants to improve this self-management task. It is not unanticipated that an improvement in sodium restriction provides such a benefit. The Heart Failure Society of America and the American Heart Association recommend that HF patients restrict dietary sodium intake to $2-3 \mathrm{~g} /$ day or less than $3 \mathrm{~g} /$ day, respectively. ${ }^{12,13}$

Several recent studies have demonstrated that self-management is a key component of HF care. Lee et al. ${ }^{14}$ reported that persons more engaged in self-management had a 56\% reduction in all-cause mortality, hospitalization, or emergency room visits than persons who were less engaged in self-management. Similarly, systematic review of randomized controlled trials demonstrated that selfmanagement decreased all-cause hospital admission by $41 \%$ and HF re-admissions by $56 \%$, which led to a reported savings of healthcare dollars of $\$ 1,300-7,517$ per patient per year. ${ }^{15}$

There are inherent limitations in the study, in that we cannot exclude unmeasured sampling bias, the Hawthorne effect, and repeated testing bias that may have occurred during the study. Althugh our study population had similar characteristics of the general population with HF, we enrolled patients from the Advanced Heart Failure Clinic at a large academic medical center, who may not be representative of the general population with HF. The potential for the Hawthorne effect and repeated testing bias may have similar effects in this study design. However, we attempted to negate these effects in the variety of outcomes measured. Although NYHA class, MLHFQ, and self-reported activity and self-management tasks could be subject to these forms of bias, it is unlikely that the patient's physical exam would also be affected. The multiple outcome variables trending in the same direction strengthens our results.

\section{Conclusions}

A Web application for self-monitoring HF over 12 weeks improved both NYHA classification and MLHFQ score. There were also trends in the improvement physical activity and physical exam. Patients reporting a sodium-restricted diet increased over the 12-week period, which may have led to the positive findings. A large-scale study is needed to further investigate the effects of this Web application on hard clinical end points in a randomized controlled design.

\section{Disclosure Statement}

No competing financial interests exist. 


\section{DORSCH ET AL.}

\section{REFERENCES}

1. Go AS, Mozaffarian D, Roger VL, Benjamin EJ, Berry JD, et al. Heart disease and stroke statistics-2014 update: A report from the American Heart Association. Circulation 2014;129:e28-e292.

2. Krumholz H, Amatruda J, Smith G, et al. Randomised trial of an education and support intervention to prevent readmission of patients with heart failure. J Am Coll Cardiol 2002;39:83-89.

3. Blue L, Lang E, McMurray J, et al. Randomised controlled trial of specialist nurse intervention in heart failure. BMJ 2002;323:715-718.

4. Jaarsma $R$, Halfens $R$, Huijer Abu-Saad $H$, et al. Effects of education and support on self-care and resource utilization in patients with heart failure. Eur Heart J 1999;20:673-682.

5. Bjorck-Linne A, Liedholm $H$, Israelsson B. Effects of systematic education on heart failure patients' knowledge after 6 months. A randomised, controlled trial. Eur J Heart Fail 1999;1:219-227.

6. Carlson B, Riegel B, Moser DK. Self-care abilities of patients with heart failure. Heart Lung 2001;30:351-359.

7. Kubo SH, Schulman S, Starling RC, Jessup M, Wentworth D, Burkhoff D. Development and validation of a patient questionnaire to determine New York Heart Association classification. J Card Fail 2004;10:228-235.

8. Lee KS, Lennie TA, Warden S, Jacobs-Lawson JM, Moser DK. A comprehensive symptom diary intervention to improve outcomes in patients with HF: A pilot study. J Cardiac Fail 2013;19:647-654

9. Caldwell MA, Peters KJ, Dracup KA. A simplified education program improves knowledge, self-care behavior, and disease severity in heart failure patients in rural settings. Am Heart J 2005;150:983-988.

10. Doughty RN, Wright SP, Pearl A, Walsh HJ, Muncaster S, Whalley GA, Gamble G, Sharpe N. Randomized, controlled trial of integrated heart failure management. The Auckland Heart Failure Management Study. Eur Heart J 2002;23:139-146.
11. Wright SP, Walsh HJ, Ingley KM, Muncaster SA, Gamble GD, Pearl A, Whalley GA, Sharpe N, Doughty RN. Uptake of self-management strategies in a heart failure management programme. Eur J Heart Fail 2003;5:371-380.

12. Lindenfeld J, Albert NM, Boehmer JP, et al. Executive summary: HFSA 2010 comprehensive heart failure practice guideline. J Card Fail 2010;16:475510.

13. Yancy CW, Jessup M, Bozkurt B, et al. 2013 ACCF/AHA guideline for the management of heart failure: $\mathrm{A}$ report of the American College of Cardiology Foundation/American Heart Association task force on practice guidelines. Circulation 2013;128:1810-1852.

14. Lee CS, Moser DK, Lennie TA, Riegel B. Event-free survival in adults with heart failure who engage in self-care management. Heart Lung 2011;40:12-20.

15. Jovicic A, Holroyd-Leduc JM, Straus SE. Effects of self-management intervention on health outcomes of patients with heart failure: A systematic review of randomized controlled trials. BMC Cardiovasc Disord 2006;6:43.

Address correspondence to: Michael P. Dorsch, PharmD, MS University of Michigan College of Pharmacy Victor Vaughn Building, Room \#311

1111 East Catherine St. Ann Arbor, MI 48109-2054

E-mail:mdorsch@med.umich.edu

Received: May 12, 2014

Accepted: June 30, 2014 


\section{This article has been cited by:}

1. Dang Stuti, Karanam Chandana, Gómez-Marín Orlando. 2017. Outcomes of a Mobile Phone Intervention for Heart Failure in a Minority County Hospital Population. Telemedicine and e-Health 23:6, 473-484. [Abstract] [Full Text HTML] [Full Text PDF] [Full Text PDF with Links]

2. Joanne Greenhalgh, Sonia Dalkin, Kate Gooding, Elizabeth Gibbons, Judy Wright, David Meads, Nick Black, Jose Maria Valderas, Ray Pawson. 2017. Functionality and feedback: a realist synthesis of the collation, interpretation and utilisation of patient-reported outcome measures data to improve patient care. Health Services and Delivery Research 5:2, 1-280. [CrossRef]

3. Maria Francesca Romano, Maria Vittoria Sardella, Fabrizio Alboni. 2016. Web Health Monitoring Survey: A New Approach to Enhance the Effectiveness of Telemedicine Systems. JMIR Research Protocols 5:2, e101. [CrossRef]

4. Enrico Capobianco. 2015. On Digital Therapeutics. Frontiers in Digital Humanities 2. . [CrossRef] 